Research Article

Iuliia Lashchuk*

\title{
Displaced Art and the Reconstruction of Memory: Ukrainian Artists from Crimea and Donbas
}

https://doi.org/10.1515/culture-2018-0063

Received April 25, 2018; accepted November 29, 2018

\begin{abstract}
After the occupation of Crimea and the conflict in Eastern Ukraine, many people were forced to leave their homes and look for a new place to live. The cultural context, memories, narratives, including the scarcely built identity of artificially made sites like those from Donbas (Donetsk and Luhansk regions) and the multicultural identity of Crimea, were all destroyed and left behind. Among the people who left their roots and moved away were many artists, who naturally fell into two groups-the ones who wanted to remember and the ones who wanted to forget. The aim of this paper is to analyse the ways in which the local memory of those lost places is represented in the works of Ukrainian artists from the conflict territories, who were forced to change their dwelling- place. The main idea is to show how losing the memory of places, objects, sounds, etc. affects the continuity of personal history.
\end{abstract}

Keywords: migration, exile, nomad, memory, home

\section{Introduction}

What do we imagine when we hear the word "migration"? How do we imagine migrants without even seeing them? Our imagination, which is so rich in other contexts, in this particular case always creates pretty much the same simplified picture. Inside or outside their own country, migrants are always "strangers at our door," as Zygmunt Bauman wrote in his book of the same title (Strangers at Our Door). Even though migration/movement/changing places is a natural human need and right, which has existed since the beginning of civilisation, today's migration is considered a crisis. Caused mostly by economic and political reasons, migration has become a danger, which people try to keep as much as possible at arm's length. Nevertheless, anyone can become a migrant by being forced to move for a variety of reasons and be turned into the Stranger.

Seyla Benhabib, an American philosopher of Turkish-Sephardic roots, uses the metaphor of exile to describe the critical social situation of being "beyond the walls." (206) Migrants occupy the third place: a place in-between. Benhabib describes this situation of exile as linear, non-political and representing a space that does not exist. Indeed many migrants and refugees take up this in-between place, living far from home without the possibility of going back, and without any chance of becoming a part of the society in the place where they are now living. As they are ghettoised by the new local communities in which they find themselves, they lose the opportunity to communicate with locals and the wall between them becomes even higher.

*Corresponding author: Iuliia Lashchuk, Institute of Philosophy, University of Warsaw, 00-927 Warsaw, Poland, E-mail: yulia.lashchuk@gmail.com 
In the situation I am discussing here there is a phenomenon I consider interesting-that of the nomadDeleuze and Guattari's term for a type of modern stranger-and nomadism, a nonlinear, active, even politically engaged style of being, reinterpreted by Rosi Braidotti.

However, Braidotti distinguishes between three types of people:

- the migrant-economic migrant (usually working class);

- the exile-depending on the political situation and political views of the person (usually middle class);

- the nomad - the person without class, an intellectual, a polyglot (if we talk of nomads, we are talking more generally about nomadic thinking, as in Deleuze and Guattari's theory of the rhizome). (57-59)

I have to disagree with this differentiation because I do not know where I would place the category I am referring to. The people I am discussing, artists and curators from Donbas and Crimea, are migrants, because they went from a poorer country to a richer one or from one region to another; they are exiles, because they had to escape for political reasons; and most importantly, they are nomads, because of the physical movement and not belonging to the new place, but also because of being artist-intellectuals and becoming nomadic through the reconstruction of their memory. In her book about nomadic theory Braidotti describes the process of becoming nomadic as follows: "Becoming nomadic means one learns to reinvent oneself and one desires the self as a process of transformation. It's about the desire of change, for flows and shifts of multiple desires" (Braidotti, Nomadic Theory 41). In this paper I'll try to show a process of such reinvention by using Braidotti's cartographic method, whose aim is "to provide a politically grounded and theoretically infused account of the webs of power relations we are all entangled in" (Braidotti, Posthuman Critical Theory 15), which will help me to name the problem and place it on the map, where art, migration and politics meet.

My analysis in this paper is based on the project Reconstruction of Memory, led by Andrii Dostliev and Lia Dostlieva, artists and curators from Donetsk (the capital of the Donbas region of Eastern Ukraine, the heart of the occupied territories), who currently live in Poland. Focusing specifically on the experience of the artists involved in the project, this paper analyses the meaning of their personal experience in their process of creation. My text combines a philosophical discussion of memory and home with an explanation of concrete cases represented in the art-project Reconstruction of Memory. Among other things, it analyses a work named Occupation (2015, collage, series of 31 pictures) by Andrii Dostliev, which consists in the process of recreation of his lost past through occupying the lost memories of others. Another important topic is the phenomenon of the ideal home as shown in Emine Ziyatdinova's video installation Home (2016). My discussion will focus on how losing your home for political reasons and being forced to migrate can be a reason for objectifying remembrance. This text is based on interviews with the curators and artists of the project Reconstruction of Memory Lia Dostlieva and Andrii Dostliev during the exhibition Reconstruction of Memory in the Ukrainian House in Warsaw (July 2-10, 2016).

\section{The Context}

The story of the project began in 2014, right after the Euromaidan (or Maidan) revolution which began on the night of November 21, 2013, with public protests in Maidan Nezalezhnosti ("Independence Square") in Kyiv after Yanukovych (the former president of Ukraine) refused to sign trade deals with the EU. In the aftermath of that revolution, first, the Crimean Peninsula was annexed, which led to the declaration of Crimea's independence on March 16, 2014, with its subsequent incorporation by Russian Federation two days later and then came the turn of the Donbas region to be in danger of annexation. During this time "proUkrainian" activists, among many other cultural activists, writers and artists, were trying to demonstrate their views, risking their lives by gathering in the city centre of Donetsk with national flag of Ukraine in order to confront the "anti-Maidan" and "pro-Russian" protests that commenced in the city and led to the formation of the self-proclaimed Donetsk and Luhansk People's Republics (DPR and LPR). Donetsk became extremely dangerous for those people with pro-European views who were trying to take a political stand. To be able to speak and even to stay safe, they had to escape from their hometown. After having declared 
DPR and LPR, "pro-Russian" separatists were trying to take control of strategic items of infrastructure across Donbas such as government buildings in Mariupol, Sloviansk, Kramatorsk, Druzjkivka, Artemivsk and other cities as well as Donetsk airport, which set off an armed conflict and the so-called "anti-terror" operation launched by Ukrainian government.

At the time these events were unfolding in Ukraine, Andrii Dostliev, a Ukrainian artist from the Donbas region, was doing his masters in Poznan. His wife Lia, along with their seven-year-old son, came to visit him in Poland at the very start of the fight for Donetsk airport, a fight that lasted 242 days between May 2014 and January 2015 and would later be described as one of the bloodiest battles in that conflict (Donetsk airport: Strategic Rubble of High Symbolic Value).

Their house in Donetsk was near the airport, and going back to the city would have been tantamount to committing suicide. Moreover, they had no idea whether their flat was not taken by someone else or even if it was still standing. Lia, who had come to Poland for a few weeks with her child and a small backpack, had to stay, leaving behind everything they had, like many of those 1.8 millions of internally displaced persons (UNHCR Operational Update on the Ukraine Situation), separated from their homes by shelling, roadblocks and checkpoints.

It took them some time to more or less set up their lives in this new place and take enough distance from the events happening in Donetsk to analyse them. It also took them time to be able to speak at last about what had happened. As the Holocaust survivor Sonia Schreiber Weitz wrote: "To speak is impossible, and not to speak is impossible" (qtd. in Caruth 154). The circumstances were different, but they felt exactly the same. Lia and Andrii Dostliev talked a lot with their friends, who had also had to move in order to save their lives and protect their beliefs. It became clear that this sudden forced displacement cost them not only material losses but much more: it affected the personal stories of each one of them. Their roots were cut off, and their memories were becoming less and less clear. They write:

While packing documents and money in a hurry, we've left scattered grandmother's photo albums, mother's jewellery, and our first toys, all those trinkets that used to mark our progress in time. Those are the things that no one would rescue. They are useless for settling down in a new place. They would not make your new life better. For many years, we've been stockpiling those silent witnesses of our existence only to abandon them in a critical moment, thus depriving ourselves of material memories. The scale of this trauma is yet to be estimated. Cut off from our roots, deprived of past, uncertain about future, lacking support in the present, we are unable to move further until this loss is apprehended, described, and analysed, and until the emptiness caused by it is filled again. (Reconstruction of Memory | Curatorial Project by Lia Dostlieva and Andrii Dostliev)

And so began the Reconstruction of Memory project.

Let us continue with identity. I shall focus on how the identity of a place had an influence on the identities of the people who lived there. The regions I am referring to are very specific. The cities of the Donbas region were mostly artificially created by the Soviet government around newly built factories and mines. People were brought in from all over the Soviet republics; many forced to move there, such as families from Western and Central Ukraine. Being moved to purpose-built towns, they did not have a personal history in common. All those people came from different parts of the USSR; they brought to the Donbas region their own languages, memories and identities and their different reasons for moving. In the light of this, they had to build a new common identity for everybody, which was extremely hard. There was no common memory, no common heroes and of course no true common history. New narratives were written for these people. They had no local history, myths and heroes, and so an identity was created and imposed on the people. For example, a significant impact upon Donbas identity was imposed by the mythologies of Stakhanovite movement which were based on a story about Soviet coal miner Aleksei Stakhanov, "whose name became the catchword for the super-worker in the nineteen thirties and forties, has been restored to public attention by being designated a Hero of Socialist Labor” (Soviet Honors Original Stakhanovite).

Another region-Crimea-had always been multicultural, but many ethnicities living there managed to create a common identity by calling themselves Crimeans. This region was specific because it was owned by the Ottoman Empire, the Russian Empire, Ukraine, inhabited by Persians, Greeks, Bulgars, Crimean Tatars, Krymchaks, Karaites, Ukrainians, and Russians and it had many memories which looked like a 
palimpsest of all those cultures, so that to find the authentic one would be impossible. They all became equally authentic-or inauthentic.

\title{
Occupation
}

Andrii Dostliev's work Occupation (2015) discusses the need to reconstruct his family's visual memory as a benchmark for his own personal memory. In his manifesto he writes:

\begin{abstract}
My family photo archive still remains there in my flat. I might never see it again. It might not exist anymore when I'm writing this text or when you will be reading it. Attempts to retrieve it may produce unnecessary risks for those who would be assisting me. All I can do to preserve my family's visual history is to reconstruct at least those photos which I still remember. Reconstruct using any available materials and photos of other people no longer needed by their previous owners. Occupy somebody else's memorabilia exactly the same way my own were occupied. (Reconstruction of Memory 1 Curatorial Project by Lia Dostlieva and Andrii Dostliev)
\end{abstract}

An old album with pictures of an unknown family was to become part of his own past. Andrii Dostliev bought it on the flea market. From it, he chose 31 pictures (one for each year of his life) and adjusted those pictures to his memories, collaging them with the details he needed or simply blotting out the parts he did not need. Dostliev did not know the people portrayed in the pictures; he could not ask them why they gave away their family album, whether they were still alive or how this family ended up. He did not care about those people and their memories. Just like the soldiers who came and occupied his memories without even knowing him, he occupied someone else's memories. Occupation becomes a tool for creating a completely new narrative; it denies any reflection on someone's personal story. In his text The Revelation of the World that was Always Already There... Rick Dolphijn writes about the Deleuzian concept of 'occupation' as "the greatest power of art." "In occupying that which is loved so dearly, great literature, great music, is able to reveal another world. A world that is completely new yet always already there. The power of art is thus about addressing human deafness and human blindness" (185). The people in the pictures are forgotten, as are any details which could tell us anything about them. All their memories happened to fall into the hands of a random person who was looking for his own memories. The occupation of the memories happened in the same way as the occupation of the territory of Donbas.

Having been raised in Brianka, a small town in the Luhansk region, Andrii's personal memory was based not on the memory of the place but on the memory of situations and little details of people who lived there, and whose pictures were collected in the old album, which remained in occupied Donetsk, as the only proof of his past. Remembering himself among those people, places and colours places him in the history of his family, as well as placing his family in a bigger social context. By materialising his own memories, he felt present in the community where he used to live. Many of the people in the pictures had moved away or died physically or symbolically, but the faces in the lost pictures remained in the time when there was no war when the personal history of the author was logical and clear. When it was lost, the album took with it the belief that the town, as well as the artist's past life, had ever existed. His personal memory was materialised in photos, fixed there forever. But a lack of them dematerialised all the family memories. Little details from the memory of the little boy, which were part of his personal and also the common memory of his family, started to disappear. All the faces and stories were becoming less and less clear, so in order to keep the whole picture, his consciousness started to recreate the missing parts. The story became a mixture of truth and figments of the artist's imagination, and thus the borders between them became so thin that they were lost with time.

As we can see, in this concrete case we cannot talk about a lost memory of the place as such. I prefer to call it a situation of loss. The source of the creation was not the physical space but rather its absence, which affected the personal history of this particular family. How many such families experienced a loss for different reasons? The artist does not mention any of them. His personal trauma of loss is so strong that it has to be worked out at any cost, even by using the very same methods he suffered from.

In the 1930s Walter Benjamin wrote: "Memory is not an instrument for surveying the past but its theatre. 
It is the medium of past experience, just as the earth is the medium in which dead cities lie buried. He who seeks to approach his own buried past must conduct himself like a man digging” (xii). Dostliev is not only digging, but he is also the archaeologist of his family's visual history. He discovers some pieces from his memory and builds his story based on them. This story has lost its linearity and is now reminiscent of Deleuze and Guattari's rhizome. It could have been written in a different way, depending on the author's choice. The theatre of memory referred to by Benjamin perfectly fits the Occupation project. What seems real can easily become an invention. The pictures of strangers play their roles when written by the memory and/or imagination of the artist.

The pictures I would like to analyse are:

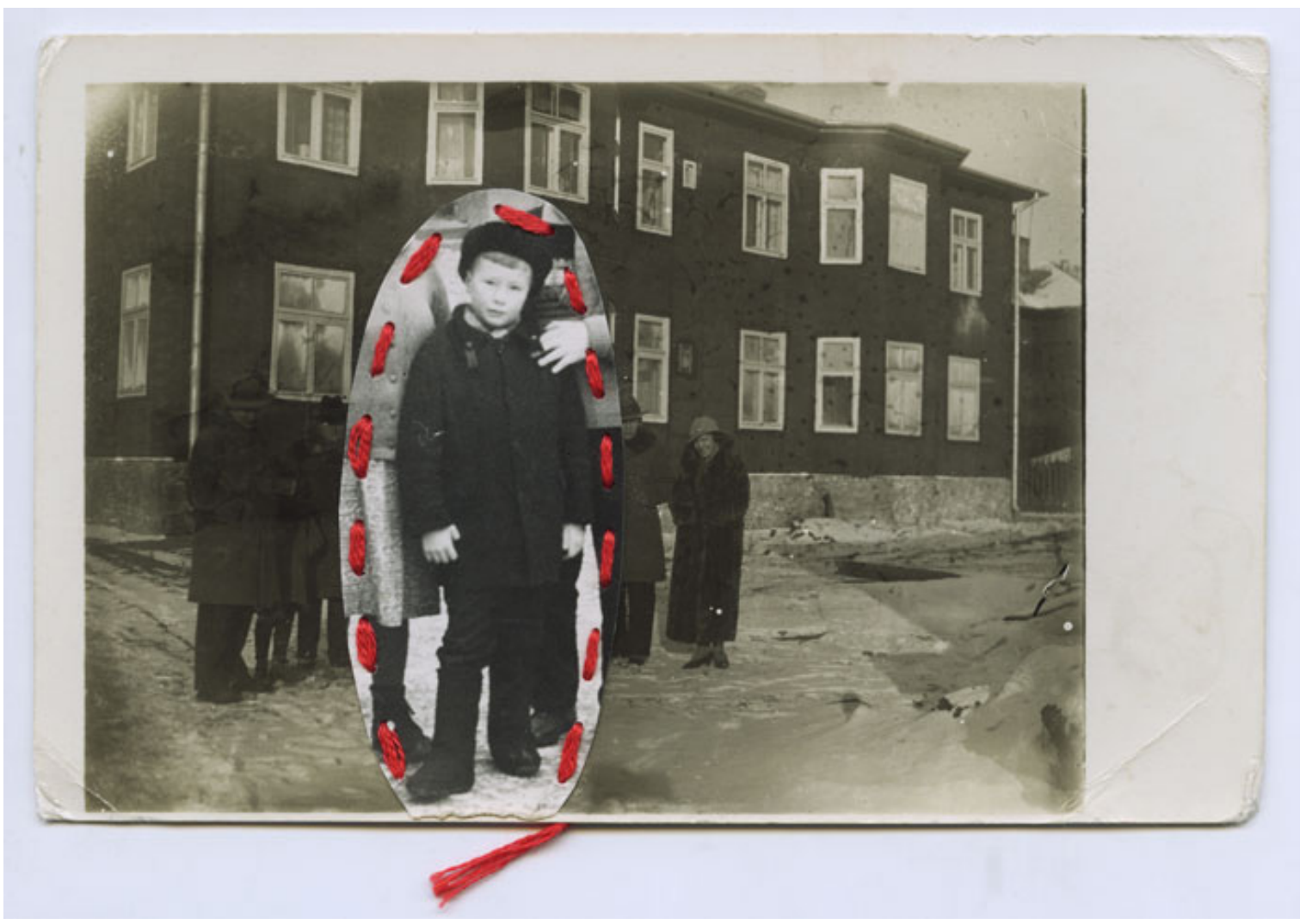

Figure 1. A boy with a camera

Dostliev's description of the work is as follows: "My uncle got an amateur camera as a birthday present when he was a teenager and we have (had) several boxes of his photos-there were dogs, cats, neighbours, trees, selfies and a single picture of our old house (top floor, two windows on the right) in a small town in the Luhansk region of Ukraine."

(Reconstruction of Memory / Curatorial Project by Lia Dostlieva and Andrii Dostliev)

When we look at this picture, the first thing we see is the disproportionately large figure of the "uncle," who supposedly took the picture, but who is placed inside it with other "members of the family." His figure is sewn into the picture with a red thread, which reinforces, even more, the strangeness of this person here, but at the same time proves his importance in the author's story. 


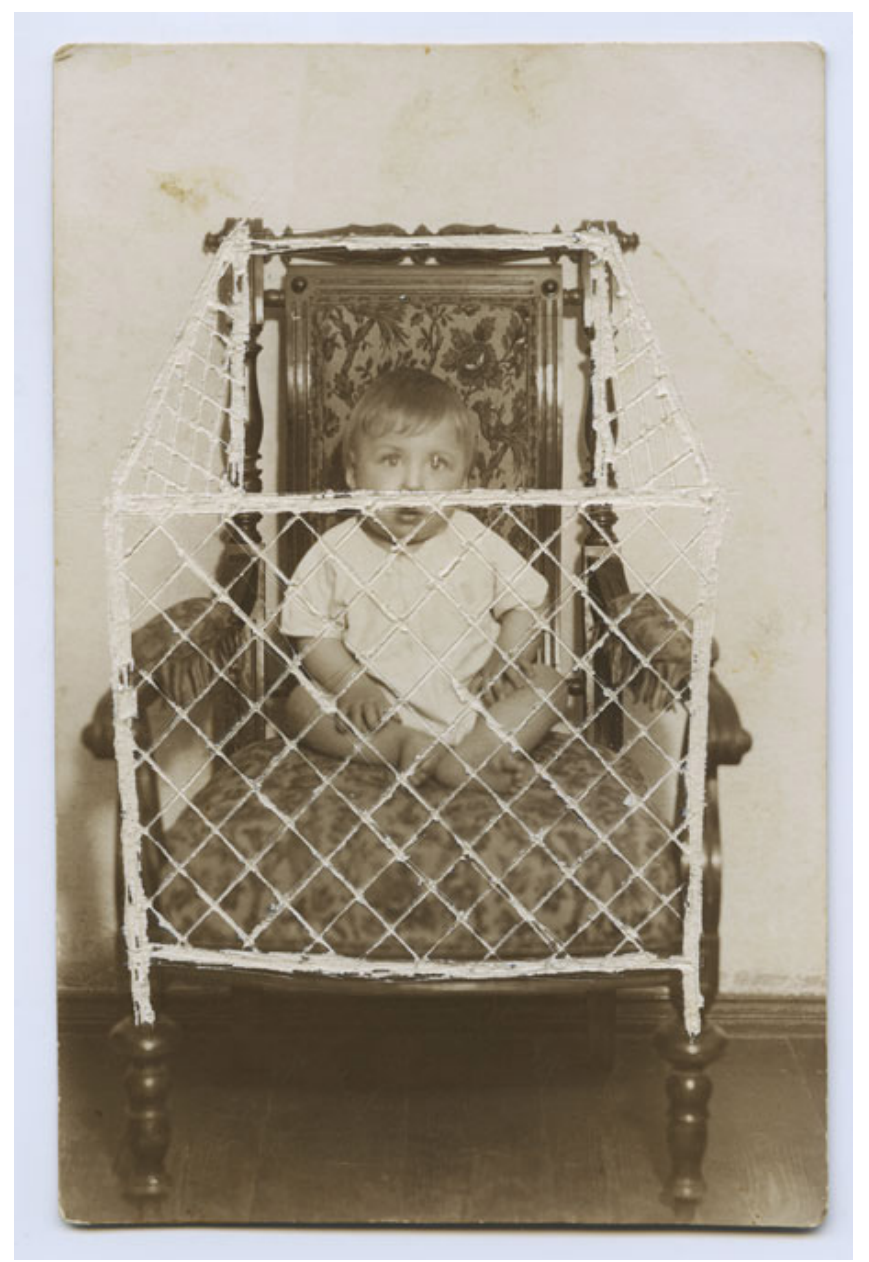

Figure 2. A child in the crib

"My first photo. I'm 10 months old or so, I'm standing in my baby crib behind a safety net. Everything is blurred and barely visible, just like my memories.” (Reconstruction of Memory / Curatorial Project by Lia Dostlieva and Andrii Dostliev)

Here the artist is trying to reinsert himself into his childhood memories by constructing a fake picture of himself. His forgetting of the past is, first and foremost, an act of forgetting himself in the past. There are very few pictures of the artist's childhood and of himself. Every version is different, even the little boys (who now play the role of him as a child) are placed in different situations. They are not proportional; they even have different faces-it is not the same child. But this does not matter. The author does not care how they look, who they really are or how they are dressed. His task is to give them as many details as he can remember. Adding new elements creates a different scenario of the little boy's life, making the artist's own identity rhizomatic, nomadic-available in different variants. 


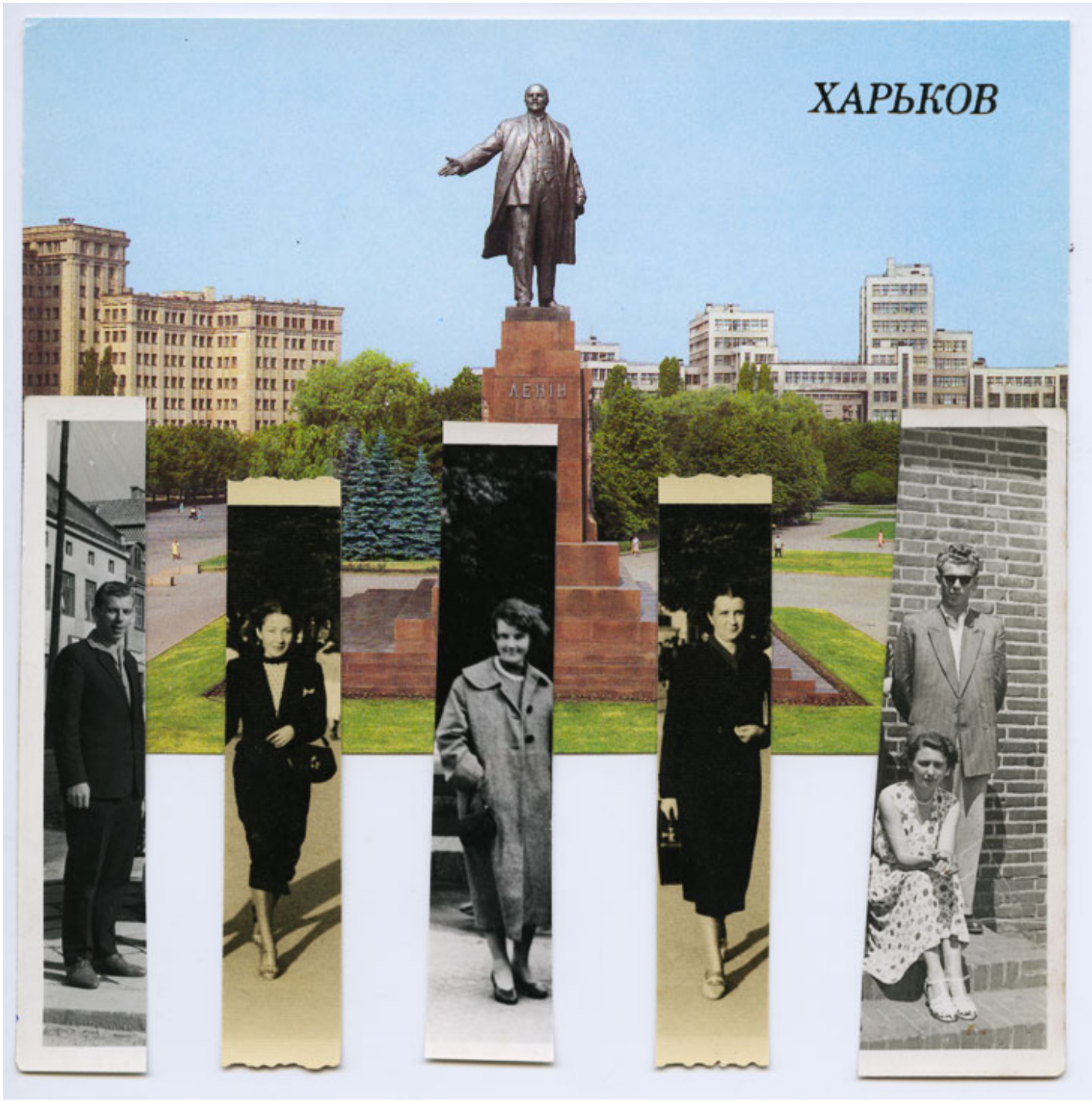

Figure 3. Mother

"This photo is my mother's-taken during her student years in Kharkiv. She's standing with her friends near the monument of Lenin in the central square. The same monument that was finally demolished in 2014 by Maidan activists." (Reconstruction of Memory / Curatorial Project by Lia Dostlieva and Andrii Dostliev)

This picture is an example of how, in the artist's imagination, those three moments (times in his memory) mesh together, interacting with each other to create only one span of time, which brings the memories closer to each other and makes the relation between them highly logical: the time when his mother was a student; 2014, when Lenin's monument in Kharkiv was demolished (September 2014) as part of a wider mass public movement, known in Ukraine as "Leninopad" which began during Maidan (November 2013March 2014) followed by the process of decommunisation; and the present, the actual time of the artist, when Lenin no longer exists, just like his mother, who stayed in that past life.

Dostliev's relation with his mother is very important here. He does not mention his father at all, but his mother appears many times, mostly represented at a moment when the artist himself was not yet born. We see here a moment of initiation. The symbolic death of the mother in 2014 was very traumatic for the artist. Even though she is still alive, for him she does not exist anymore. It was not a natural process, but a sudden politically-based situation that took him away from his mother. Maybe that is why he chose to resurrect her in the past. 


\title{
Home
}

Another artist taking part in the Reconstruction of memory project is Emine Ziyatdinova-a UkrainianCrimean artist born in Uzbekistan to a family of Crimean Tatars, who were deported there by Stalin from the Crimean Peninsula between 1943 and 1944. After 1989, many deported families went back to Crimea, including that of Emine. In 2014, the story repeated itself. After the Russian annexation of the peninsula, many Crimean Tatars left their homes and those who stayed and did not agree to collaborate with the proRussian government disappeared or were found dead. Her project "explores the existence of the Crimean Tatar identity and the collective memory within the complex political discourse after the annexation" (Reconstruction of Memory / Curatorial Project by Lia Dostlieva and Andrii Dostliev).

Home (2016) is the set of parallel videos, which play consecutively on two individual monitors, in which the main characters are Ziyatdinova's grandmother, mother and herself. It shows the daily life of the family inside the house, the artist's family home in Crimea. We can hear the audio of a conversation about their lives and the situation in Crimea, which is interrupted by the loud voice of pro-Russian, pro-Ukrainian and Crimean Tatar public speeches on the current situation in Crimea. "It will reflect on the current situation Crimean Tatars found themselves in when all public discussions were pushed into the kitchen space" (Reconstruction of Memory / Curatorial Project by Lia Dostlieva and Andrii Dostliev). The work suggests that you can discuss it with your close family, whom you can trust, but even then you whisper about it. It is impossible to escape the political changes and propaganda even in private space: each side demands that you make a choice and identify yourself in this political system of opposites.

This situation of otherness (strangeness) and always being on the move became the personal story of the artist's family. The feeling of being stuck in the middle, being at home but never at home, makes her personal experience even more traumatic than Dostliev's. Born and raised in a foreign country, she dreamt of going back to Crimea, her ideal home that had been taken away from her grandparents. But when she finally went back, she lost it again and had to move to Kyiv leaving her family. Would it have been better or less traumatic if they had never gone back?

What is most important in Home is that in her video the artist shows three women-her grandmother, her mother and herself, representing three generations of the same personal traumatic female experience. In the Ukrainian traditional culture, the woman is supposed to protect her own house, but these women are unable to do that. The home is taken away again, the chain of female home-continuity is broken.

Cathy Caruth writes:

\begin{abstract}
Traumatic experience, beyond the psychological dimension of suffering it, involves, suggests a certain paradox: that the most direct seeing of a violent event may occur as an absolute inability to know it; that immediacy, paradoxically, may take the form of belatedness. The repetitions of the traumatic event-which remain unavailable to consciousness but intrude repeatedly on sight-thus suggest a larger relation to the event that extends beyond what can simply be seen or what can be known, and is inextricably tied up with the belatedness and incomprehensibility that remain at the heart of this repetitive seeing. (91-92)
\end{abstract}

I find this description highly interesting because it shows us traumatic experience as a person's psychological suffering, but also as a basis for personal history, which we can extend to the history of the whole nation (Crimean Tatars, in the case of Ziyatdinova). Repeating the traumatic event, along with the situation of loss, brings the feeling of belonging-both to the discriminated group and also to the place which was taken away again. A traumatic history creates a traumatic identity, which is taken and accepted by the artist as some kind of nostalgia and responsibility.

Ziyatdinova's repetition of the traumatic experience is different from Dostliev's. Her traumatic memory is strictly related to the lost territory and multiple moves, whereas his traumatic memory is related to losing artefacts or physical representations of memory. Being the Other in a location, the author of Home is a Stranger, who came from a different place, while the author of Occupation is an unknown Other, who came from nowhere. The newly created identity of Ziyatdinova is based on the memories of loss; the identity of Andrii Dostliev is based on his lack of memories. Both artists deal with the image of the mother. Dostliev voluntarily cuts his present ties to his mother, trying to re-create and re-interpret his personal history, 
memorialising her in the past. However, Ziyatdinova underlines the female continuation of the personal trauma of her family, emphasising like Luce Irigaray the importance of "mother-daughter" relations in creating a personal genealogy (60).

\section{Conclusions}

The two examples discussed above demonstrate the experience of loss in different ways. That was the idea of the Reconstruction of Memory project-to show the diversity of traumatic experiences. This project is a dialogue between those who are perceived as Others (strangers) and those who are Selves (locals). This is an attempt by a group of artists to explain, share and become closer, putting their reconstructed memories into a common box, and to identify themselves in their new place, where they are strangers. Caruth writes about the belated experience of trauma, giving a definition of post-traumatic stress disorder (PTSD). She claims that the personal experience of trauma is always related to possession:

the pathology cannot be defined either by the event itself-which may or may not be catastrophic and may not traumatize everyone equally-nor can it be defined in terms of a distortion of the event, achieving its haunting power as a result of distorting the personal significances attached to it. The pathology consists, rather, solely in the structure of its experience or reception: the event is not assimilated or experienced fully at the time, but only belatedly, in its repeated possession of the one who experiences it. To be traumatized is precisely to be possessed by an image or event. (Caruth 4-5)

According to research published by International Alert, 32\% of internally displaced persons (IDPs) in Ukraine suffer from post-traumatic stress disorder as a result of the armed conflict in the east, with a high prevalence of mental disorders such as depression (22\%) and anxiety (17\%), which is especially high among women. Research says that 74\% of IDPs who need psychiatric care do not receive it (In war-torn Ukraine, $32 \%$ displaced persons suffer from PTSD-study). Can artistic expression be this kind of care? For Deleuze and Guattari artworks were "blocs of sensation" whose "validity lies in themselves and exceeds any lived" (167), Elisabeth Grosz goes further and claims that "art is of the animal. It comes, not from the reason, recognition, intelligence, not from a uniquely human sensibility, or from man's higher accomplishments, but from something excessive, unpredictable, lowly" (63). Could it then come from fear, pain, or a feeling of loss or maybe from not being able to remain silent? The Reconstruction of Memory project became a kind of therapy for artists who lost physical representations of their memories when they were forced to move. Now that they have remembered and described what was taken from them, they can possess it, easily deny it, or even forget it again. But now this is their own choice, their freedom to forget.

\section{Works Cited}

Bauman, Zygmunt. Strangers at Our Door. John Wiley \& Sons, 2016.

Benhabib, Seyla. Situating the Self: Gender, Community and Postmodernism in Contemporary Ethics. Polity Press, 1992.

Benjamin, Walter. A Berlin Childhood around 1900. [Kindheit um Neunzehnhundert, 1950]. Translated by Howard Eiland, Belknap Press, Harvard University Press, 2006.

Braidotti, Rosi. Nomadic Subjects: Embodiment and Sexual Difference in Contemporary Feminist Thought. Columbia University Press, 1994.

Braidotti, Rosi. Nomadic Theory: The Portable Rosi Braidotti. Columbia University Press, 2011.

Braidotti, Rosi. Posthuman Critical Theory. Critical Posthumanism and Planetary Futures, edited by Debashish Banerji and Makarand R. Paranjape. Springer, 2016.

Caruth, Cathy. Unclaimed Experience: Trauma, Narrative, and History. Johns Hopkins University Press, 1996.

Caruth, Cathy. Trauma: Explorations in Memory. Johns Hopkins University Press, 1995.

Deleuze, Gilles and Félix Guattari. A Thousand Plateaus: Capitalism and Schizophrenia. [Capitalisme et schizophrénie 2: Mille plateaux, 1980]. Translated by Brian Massumi. Continuum, 2004.

Deleuze, Gilles and Félix Guattari. What Is Philosophy? [Qu'est-ce que la philosophi? 1991]. Translated by Hugh Tomlinson and Graham Burchell, Columbia University Press, 1994.

Dolphijn, Rick. "The Revelation of a World that was Always Already There: The Creative Act as an Occupation." This Deleuzian Century: Art, Activism, Life, edited by Rosi Braidotti and Rick Dolphijn. Brill Rodopi, 2014 
Dostlieva, Lia, Dostliev, Andrii Reconstruction of Memory | Curatorial Project by Lia Dostlieva and Andrii Dostliev. 2016. www. reconstructionofmemory.org/en.

Irigaray, Luce. “And the One Doesn't Stir Without the Other” [Et l'une ne bouge pas sans l'autre, 1979]. Translated by Helene Vivienne Wenzel, Signs: Journal of Women in Culture and Society, vol. 7, no. 1, 1981.

Goncharenko, Roman. Donetsk airport: Strategic rubble of high symbolic value. 20 January 2015. www.dw.com/en/donetskairport-strategic-rubble-of-high-symbolic-value/a-18203321

Grosz, Elizabeth. Chaos, Territory, Art: Deleuze and the Framing of the Earth. Columbia University Press, 2008

"Soviet Honors Original Stakhanovite" New York Times 25 September 1970. www.nytimes.com/1970/09/25/archives/soviethonors-original-stakhanovite.html “In war-torn Ukraine, 32\% displaced persons suffer from PTSD-study." International Alert 07 June 2017. https://www.internationalalert.org/sites/default/files/Ukraine_HiddenBurdensConflictIDPs_ EN_2017.pdf

“UNHCR Operational Update on Ukraine Situation.” UNHCR report 2017. http://reporting.unhcr.org/Ukraine 